\title{
Thoracic aortic dissection mimicking primary hematological disorder: A case report
}

\author{
Mohamad Nazrulhisham Mad Naser *1, Bee Ping Chong², Noor Khairiah A. Karim³ \\ ${ }^{1}$ Department of Cardiology, Hospital Pulau Pinang, Jalan Residensi, Georgetown, Pulau Pinang, Malaysia \\ ${ }^{2}$ Department of Medicine, Faculty of Medicine, University of Malaya, Kuala Lumpur, Malaysia \\ ${ }^{3}$ Cluster of Regenerative Medicine, Advanced Medical and Dental Institute, Universiti Sains Malaysia, Bertam, Kepala Batas, \\ Pulau Pinang, Malaysia
}

Received: May 7, 2016

DOI: $10.5430 /$ crim.v3n $4 \mathrm{p} 10$
Accepted: July 20, 2016

Online Published: August 14, 2016

\begin{abstract}
Chronic disseminated intravascular coagulation (DIC) is uncommon and less clinically pronounced. Its diagnosis and therapy may be further delayed due to the subtle abnormal laboratory results. This may potentially contribute to an unfavorable patient outcome. We describe a 60 -year-old lady with chronic DIC who presented with progressive and recurrent unprovoked subcutaneous hematoma for 6 months prior to presentation. On presentation, she was anemic and thrombocytopenic with a mildly deranged coagulation profile. She was suspected to have hematological malignancies therefore a bone marrow aspirate and trephine biopsy was done but revealed no abnormality. Serial DIC panel revealed persistent low fibrinogen and elevated d-dimer which were consistent with chronic DIC. When she was referred to our centre, baseline chest radiograph showed mediastinal widening and subsequent computed tomography (CT) imaging confirmed the presence of Standford A dissection of thoracic aortic aneurysm. The gradual occult blood loss from the dissection lead to the consumptive coagulopathy and triggered the DIC cascade. Essentially, chronic DIC never occur alone and unprovoked, therefore the main principle of management is to recognize and address the underlying etiology in particularly aneurysms and malignancies.
\end{abstract}

Key Words: Chronic disseminated intravascular coagulation, Thoracic aortic aneurysm, Anemia, Thrombocytopenia

\section{INTRODUCTION}

Chronic disseminated intravascular coagulation (DIC) is a rare complication and less clinically pronounced compared to acute DIC. If there is suspicion of chronic DIC, one must look hard for the underlying insult which is often associated with malignancy and aneurysm. ${ }^{[1]}$ Chronic DIC may potentially decompensate into overt acute DIC if the underlying stimulus is not identified and treated successfully.

\section{CASE PRESEntation}

We present a 60-year-old lady with chronic DIC who presented with recurrent episodes of unprovoked hematoma. She first presented in December 2009 and found to have a spontaneous hematoma on her limbs. Investigations revealed isolated thrombocytopenia with platelet of $95 \times 10^{9} / \mathrm{L}$ (see Table 1). Complete blood counts with differential revealed normochromic normocytic anemia with reduced platelets. The initial DIC panel and biochemical profile were normal.

\footnotetext{
*Correspondence: Mohamad Nazrulhisham Mad Naser; Email: drnazrulcardio@gmail.com; Address: Department of Cardiology, Hospital Pulau Pinang, Jalan Residensi, Georgetown 10990, Pulau Pinang, Malaysia.
} 
She had spontaneous full recovery with normalization of platelet level.

Table 1. Serial of blood investigation results

\begin{tabular}{|c|c|c|c|c|c|}
\hline Investigations & $\begin{array}{l}\text { December } \\
2009\end{array}$ & $\begin{array}{l}\text { February } \\
2010\end{array}$ & $\begin{array}{l}\text { March } \\
2010\end{array}$ & June 2010 & Normal range \\
\hline \multicolumn{6}{|l|}{ FBC } \\
\hline $\mathrm{Hb}$ & $11.5 \downarrow$ & $9.5 \downarrow$ & 10.1 & $4.0 \downarrow$ & $12.0-15.0 \mathrm{~g} / \mathrm{dl}$ \\
\hline WBC & 7.6 & 8.8 & 6.5 & 10.5 & $4.0-10.0 \times 10^{9} / \mathrm{L}$ \\
\hline Platelet & $95 \downarrow$ & $65 \downarrow$ & 137 & $60 \downarrow$ & $150-400 \times 10^{9} / \mathrm{L}$ \\
\hline \multicolumn{6}{|l|}{ Coagulation } \\
\hline PT & Normal & Prolonged & Normal & Prolonged & \\
\hline APTT & 44 & $53.9 \uparrow$ & 42 & $\begin{array}{l}\text { Ranging } \\
41.0-46.0\end{array}$ & $38.3-45.8 \mathrm{~s}$ \\
\hline INR & 1.0 & 1.37 & 1.2 & $\begin{array}{l}\text { Ranging } \\
1.1-1.3\end{array}$ & \\
\hline TT & Normal & Prolonged & Normal & Prolonged & \\
\hline Fibrinogen & 1.8 & $0.8 \downarrow$ & 2.2 & 1.55 & $1.5-4.5 \mathrm{~g} / \mathrm{L}$ \\
\hline D-dimer & - & $300 \uparrow$ & - & $330 \uparrow$ & $<250 \mu \mathrm{g} / \mathrm{L}$ \\
\hline
\end{tabular}

Note. FBC: full blood count; Hb: hemoglobin; WBC: white blood count; PT: prothrombin time; APTT: activated partial thromboplastin time; INR: international normalized ratio; TT: thrombin time; $\uparrow$ Elevated; $\downarrow$ Reduced.

Two months after initial presentation, patient presented again with multiple bruises and unprovoked hematoma over her right arm with impending compartment syndrome. The multiple bruises were in different stages of resolution over both thighs and the hematoma at anteromedial aspect of right forearm measured approximately $12.0 \mathrm{~cm} \times 10.0 \mathrm{~cm}$. She was clinically pale without jaundice. There was no lymphadenopathy or hepatosplenomegaly. Her full blood count (FBC) at that time revealed further dropped in hemoglobin $(\mathrm{Hb})$ and platelet levels as shown in Table 1. Her white blood count (WBC) remained normal with normal differentiation. Her coagulation profile was deranged with prolonged prothrombin time (PT), activated partial thromboplastin time (APTT) and thrombin time (TT). Her fibrinogen level was low and D-dimer level was elevated. Magnetic resonance imaging of the right forearm revealed subcutaneous hemangioma of capillary type measuring $2.1 \mathrm{~cm} \times 2.0 \mathrm{~cm}$ with intramuscular hematoma at superficial compartment. The connective tissue disease screening and tumor markers were negative. A bone marrow examination was also done but it revealed no abnormality with normal cytogenetics $46 \mathrm{XX}$ karyotype. She was managed with multiple blood components transfusions and she made a good recovery with resolution of hematoma. She was subsequently discharged and her $\mathrm{Hb}$ count, platelet count and coagulation profile showed improvement when she came for her follow-up visit a month later (see Table 1). At this junction, the attending physicians were unable to finalize the diagnosis and the patient was planned for outpatient referral to our hematology unit to exclude primary hematological disorder.

However, she presented again to the same centre three months later with symptomatic anemia and massive subcutaneous hematoma over her back. Her Hb dropped to 4.0 $\mathrm{g} / \mathrm{dl}$ but she was hemodynamically stable. Her APTT and PT were intermittently prolonged and fibrinogen level was at the lower limit of normal range (see Table 1). She made an uneventful recovery after multiple blood transfusions. Upon transferring to our hematology service, all her baseline investigations were reexamined and interestingly, her chest radiograph which was initially read to be unremarkable revealed mediastinal widening with posterior tubular opacity (see Figure 1). A subsequent CT scan performed confirmed the diagnosis of thoracic aortic aneurysm. The aneurysm extended from the ascending to descending aorta and it measured $9.6 \mathrm{~cm}$ at its maximum diameter at the ascending aorta region, with the presence of Standford A dissection and mural thrombi (see Figure 2).

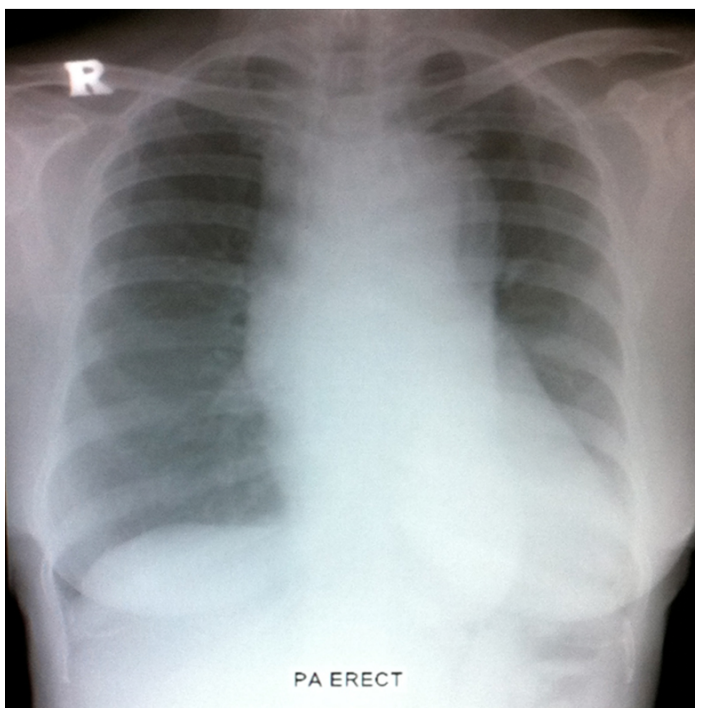

Figure 1. Chest radiograph (postero-anterior view) showing mediastinal widening with posterior tubular opacity in keeping with thoracic aortic aneurysm

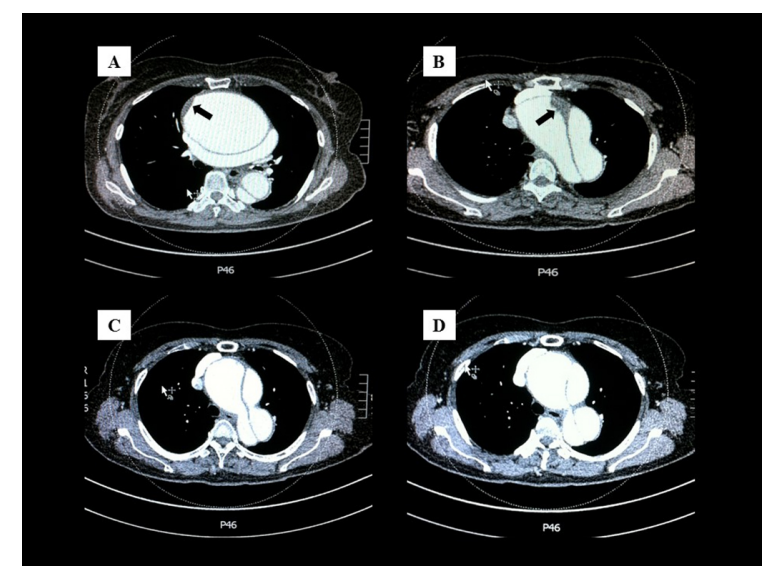

Figure 2. Axial contrast enhanced CT of thorax showing aortic aneurysm extending from the ascending to descending aorta (measuring $9.6 \mathrm{~cm}$ in maximum diameter at the ascending aorta) with presence of Standford A dissection and mural thrombi (black arrows) 
She was referred to cardiothoracic team for surgical intervention although she ultimately declined the treatment option. The risks and benefits of low molecular weight heparin (LMWH) was later discussed with the patient but she was not keen for the treatment as well. She was initially monitored at our outpatient clinic but defaulted after a few follow up visits.

\section{DisCUSSION}

The most common reported etiology for chronic DIC are malignancies and aneurysms. ${ }^{[1]}$ Other causes of chronic DIC include obstetric complications and hemangiomas. The presence of insignificant hemangioma as mentioned above in the elderly patient per se, was red herring and the failure to detect mediastinal widening on chest radiograph masquerade the more life threatening and sinister underlying pathology which was thoracic aneurysm.

Typically in chronic DIC, the degree of thrombocytopenia and coagulopathy is not markedly obvious as opposed to overt acute DIC. Patients with acute DIC are likely to be more ill, and the commonest cause is sepsis. ${ }^{[2]}$ In chronic form, the patient is relatively more comfortable, reflecting more controlled and compensated environment. The local generation of thrombin and plasmin triggered by the occult bleeding from aneurysm as illustrated in this case, leads to coagulation factors and platelets depletion but the compensatory mechanism in the liver and bone marrow are not overwhelmed.

There is currently no evidence based guideline on how to treat this group of patients. In the event of operable aneurysm, surgical correction would intervene the DIC state but not all patients will respond to it. DIC may persists despite surgery and whether this is related or induced by aortic graft itself remained unknown. ${ }^{[3,4]}$

In DIC, if the thrombosis becomes predominant, there is a role of anticoagulant. However the usage of vitamin $\mathrm{K}$ antagonist (VKA) can be detrimental in view of VKA causes acquired protein $\mathrm{C}$ deficiency which will exacerbates the prothrombic state. Moreover the longer half live of VKA is a great concern when dealing with delicate balance between thrombosis and bleeding complication. ${ }^{[5]}$ Synthetic serine protease inhibitors seemed to improve the severity of DIC in a retrospective study, but has yet been to be examined in controlled trials. ${ }^{[6,7]}$ Intravenous or subcutaneous heparin is the only effective drug available, ${ }^{[5]}$ however the indications and the dose requirements have yet to established. There is no conclusive evidence that it reduces morbidity or mortality in acute DIC. In chronic DIC secondary to aortic aneurysm (either inoperable or persistent DIC postoperatively), few case reports have showed successful treatment with subcutaneous injection of LMWH with various dose titration. ${ }^{[8,9]}$ The aim is to achieve complete clinical response as well as normalization of the clotting screen and platelet count. ${ }^{[10]}$ It may reduce morbidity in term of DIC bleeding related but may cause fatality in the event of propogation of the dissection or the aneurysmal rupture.

\section{Conclusion}

It is very essential to have high clinical suspicion of chronic DIC when presented with recurrent unexplained bleeding tendency secondary to thrombocytopenia and coagulopathy. The subsequent investigation should be directed to the cause of chronic DIC in which malignancy and aneurysm must be thoroughly excluded.

\section{CONFlicts OF InTEREST Disclosure}

The authors have declared no conflicts of interest.

\section{REFERENCES}

[1] Micallef-Eynaud PD, Ludlam CA. Aortic aneurysms and consumptive coagulopathy. Blood Coagulation \& Fibrinolysis. 1991; 2(3): 477-82. http://dx.doi.org/10.1097/00001721-19910 6000-00012

[2] Jensen R. Disseminated intravascular coagulation. Clinical Hemostasis Review. 1996; 10(5): 1-4.

[3] Kanda T, Kaneko K, Yamauchi Y, et al. Indium 111-labeled platelets accumulation over abdominal aortic graft with chronic disseminated intravascular coagulation-A case history. Angiology. 1993; 44(5): 420-4. PMid:8480923 http://dx.doi.org/10.1177/0003319 79304400514

[4] Majumdar G. Idiopathic chronic DIC controlled with low-molecularweight heparin. Blood Coagulation \& Fibrinolysis: An Interna- tional Journal in Haemostasis and Thrombosis. 1996; 7(1): 97-8. http://dx.doi.org/10.1097/00001721-199601000-00013

[5] Feinstein DI, Marder VJ, Colman RW. Consumptive thrombohemorrhagic disorders. In: Colman RW, Hirsch J, Marder VJ et al. (eds) Hemostasis \& Thrombosis Basic Principles and Clinical Practice, 4th Edition. Lippincott Williams \& Wilkins: Philadelphia. 2001: 1197-1234.

[6] Fukuda N, Shimohakamada Y, Nakamori Y, et al. Thoracic aortic aneurysm with chronic disseminated intravascular coagulation treated successfully with orally administered camostat mesilate, warfarin and aspirin. [Rinsho ketsueki] The Japanese Journal of Clinical Hematology. 2002; 43(3): 199-203. PMid:11979753

[7] Hamano K, Mizuuchi K, Kajikawa K, et al. A New Medication in Succession to Heparin for Disseminated Intravascular Coagulation Caused by Aortic Dissection-A Case Report. Bull Yamaguchi Med 
Sch. 1993; 40(1-2): 37-41.

[8] Cummins D, Segal H, Hunt BJ, et al. Chronic disseminated intravascular coagulation after surgery for abdominal aortic aneurysm: clinical and haemostatic response to dalteparin. British Journal of Haematology. 2001; 113(3): 658-60. http://dx.doi.org/10.1046/j $.1365-2141.2001 .02817 . \mathrm{x}$
[9] Garcia Fernandez JR, Lopez Berenguel F, Ais C. Long-term treatment with low molecular weight heparin, of chronic disseminated intravascular coagulation. Ann Med Interna. 2003; 20: 191-194.

[10] Majumdar G. Long-term management of chronic DIC associated with inoperable aortic aneurysm with low molecular weight heparin The Hematology Journal. 2004; 5(5): 447-8. http://dx. doi .org $/ 10.1038 / \mathrm{sj}$. thj. 6200411 